\title{
Comparison of Bipolar Diathermy Tonsillectomy Versus Cold Steel Dissection Tonsillectomy
}

\author{
Adeel Niaz, ${ }^{1}$ Muhammad Saeed, ${ }^{2}$ Hafiz Sajjad Hyder, ${ }^{3}$ \\ 1Department of ENT, Allied Hospital, Faisalabad 2,3Department of ENT, Faisalabad Medical University, Faisalabad-Pakistan
}

\begin{abstract}
Objective: To compare mean Primary Blood loss and mean time taken to complete the procedure between conventional cold steel tonsillectomy versus bipolar diathermy tonsillectomy. Study Design: Randomized Control Trial. Settings: Department of ENT Unit-I, Allied hospital, Faisalabad. Duration: 6-month duration from: May 2019 to October 2019. Methodology: After taking approval from hospital ethical committee, patients coming through the OPD who fulfilled the selection criteria were enrolled and informed consent was obtained. All the basic demographic information of each patient (Name, age, sex, address and contact) was also noted. Using computer generated random number tables patients were randomized in two groups. In Group-A patient underwent conventional cold steel tonsillectomy and in Group-B underwent diathermy tonsillectomy. All procedures were done by single surgical team to avoid the bias. From the start of the procedure till completion of tonsillectomy, the primary blood loss and time to complete the procedure was calculated. Results: Mean age was 14.83+5.84 years in Group- $A$ and $15.63 \pm 5.59$ years in Group- $B, 62.86 \%(n=22)$ in Group-A and $57.14 \%(n=20)$ in Group-B were male whereas 37.14\%(n=13) in Group-A and $42.86 \%(n=15)$ in Group-B were females. Comparison between conventional cold steel tonsillectomy versus bipolar diathermy tonsillectomy shows that $24.57+1.42 \mathrm{ml}$ in Group $-\mathrm{A}$ and $11.17+1.67 \mathrm{ml}$ blood loss in Group-B, p value was 0.001. Mean operative time (minutes) was recorded as 24.94+2.26 minutes in Group-A and 13.09+1.66 minutes in Group$B, p$ value was 0.0001 . Conclusion: We concluded that mean Primary Blood loss and mean time taken to complete the procedure were significantly lower in bipolar diathermy tonsillectomy when compared to conventional cold steel tonsillectomy
\end{abstract}

Keywords: Tonsillectomy, Bipolar diathermy, Conventional cold steel tonsillectomy, Blood loss, Operative time

Corresponding Author Submitted for Publication: 12-12-2019

Accepted for Publication: 09-04-2020

Dr. Adeel Niaz, Department of ENT, Allied Hospital, Faisalabad-Pakistan.

Email: dradeelniaz@gmail.com

Citation: Niaz A, Saeed M, Hyder HS. Comparison of Bipolar Diathermy Tonsillectomy Versus Cold Steel Dissection Tonsillectomy. APMC 2020;14(2):102-5.

\section{DOI: $10.29054 / A P M C / 2020.802$}

\section{INTRODUCTION}

Tonsillectomy forms main bulk of surgical procedures performed by ENT surgeons throughout world. ${ }^{1}$ Tonsil is common site of infection in childhood which leads to performing tonsillectomy in most of the children. ${ }^{2}$ Various techniques are used for tonsillectomy by different surgeons. Different techniques were adopted and improved to make procedure safe and reduce operative time, intraoperative blood loss, postoperative morbidity and complications. Tonsillectomy is probably one of the first procedures performed in otolaryngology. There has been a continuous evolution in surgical technique and devices over the years. ${ }^{3}$

A lot of tonsillectomy techniques have been adopted for the optimal method of tonsillectomy. The cold steel dissection method was introduced in 19th century. Later on hot techniques were used for tonsillectomy. Different hot techniques used in modern times are CO2, Nd: YAG and KTP laser, excision diathermy or plasma coblation, radiofrequency ablation, heat welding and harmonic scalpel. ${ }^{3}$ Remington-Hobbs described the use of diathermy to remove the tonsils in 1968. The veteran technique of cold dissection tonsillectomy was the gold standard for tonsillectomy for almost a centuary. ${ }^{4}$ For last 30 years hot electrosurgical techniques have been used for tonsillectomy, most commonly with diathermy. ${ }^{5}$
In diathermy tonsillectomy tissues are cut and coagulated but they also cause unintentional injury to surrounding structure and post-operative pain. Goal of procedure should be short surgical time, minimum blood loss, with early recovery. Ideally tonsillectomy procedure should have short surgical time, minimum blood loss, with quick recovery and without associated complications. Over the last few decades, electrocautery tonsillectomy has been used more widely. ${ }^{6}$

Prompt surgical technique and reduction of post-operative morbidity are the parameters that leads to assessment of best tonsillectomy technique. ${ }^{7}$ There is still a debate about the optimal method of tonsillectomy with less morbidity. Both Cold Dissection technique and bipolar diathermy tonsillectomy technique are used widely in the United States and even in Pakistan, these techniques are frequently described in the literature also. After the advent of non-explosive mixtures, the use of Bipolar diathermy became common with General inhalation anesthesia. ${ }^{8}$

Diathermy tonsillectomy allows for minimal blood loss, little operative time, and allows the simultaneous control of bleeding and dissection. However bipolar electrocautery does not cause surrounding tissue injury compared to monopolar cautery and is said to be superior in terms of perioperative bleeding and time of surgical procedure. ${ }^{9}$ 
The average blood loss per operative procedure was $24.6 \pm$ $6.12 \mathrm{ml}$ in the cold dissection group, whereas it was $10.3+2.85$ $\mathrm{ml}$ in the group of bipolar electrocautery with a $\mathrm{P}$ value of 0.001 . The average operating time of the cold dissection method was $23.50 \pm 7.10$ minutes on average compared to the dissection method of bipolar diathermy was $13.50 \pm 3.0$ minutes which is clearly showing that the Bipolar diathermy tonsillectomy is better in term of perioperative blood loss and short procedure time during tonsillectomy than cold dissection mare method. ${ }^{9}$

The rationale of this study is to compare the techniques of cold steel dissection tonsillectomy and Bipolar electrocautery in our population, so this study will help us to generate evidence for local population and best technique will be preferred with confidence to achieve good perioperative bleeding control and short procedure time.

Objective of the study was to compare mean Primary Blood loss and mean time taken to complete the procedure between conventional cold steel tonsillectomy versus bipolar diathermy tonsillectomy.

\section{METHODOLOGY}

Study Design: Randomized control trial.

Settings: Department of ENT-I, Allied hospital, Faisalabad Pakistan.

Duration: Six months from May 2019 to October 2019.

Sample Technique: Non-probability consecutive sampling technique was used.

Sample Size: Sample size was calculated using WHO sample size calculator for two mean. Anticipated population mean $=$ 23.5 Test value of population mean $=13.5$ Pooled standard deviation $=5.45$ Power of Study $90 \%$, Level of Significance $5 \%$ Sample size $=.70$ (35 in each group).

Inclusion Criteria: Patient with age $05-30$ years of both male and female gender planned for elective tonsillectomy were included.

Exclusion Criteria: Presence of peritonsillar abscess acute tonsillitis, asymmetric tonsillar hypertrophy, bleeding disorders (INR >1.5), pregnant female and lactation and underlying bleeding and clotting disorders are excluded.

Data Collection Procedure:

Patient with any contraindication e.g. IHD, Diabetes and heart disease

After taking approval from hospital ethical committee, patients coming to the OPD who fulfilled the selection criteria were enrolled and informed consent was obtained. All the basic demographic information of each patient (Name, age, sex, address and contact) was also recorded. Computer generated random number tables were used to divide patients in two groups. In Group-A patient underwent conventional cold steel tonsillectomy and in Group-B underwent bipolar diathermy tonsillectomy. All procedures were done by single surgical team to avoid the bias. From the start of the procedure till completion of tonsillectomy, the primary blood loss and time taken to complete the procedure was calculated and noted.

All the data was recorded and analysis was done using SPSS version 20. Mean and standard deviation was calculated for age. Quantitative variable (Blood loss and operative time) was presented in the form of mean + sd. Qualitative data like gender was presented in the form of frequency and percentage. Operative time, amount of blood loss was analyzed by independent sample $t$ test to see the statistical significance in two groups, $p$ value of less than and equal to 0.05 was considered significant.

\section{RESULTS}

A total of $70 \quad(n=35$ in each group) fulfilling the inclusion/exclusion criteria were enrolled to compare mean Primary Blood loss and mean time taken to complete the procedure between conventional cold steel tonsillectomy versus bipolar diathermy tonsillectomy.

Age distribution of the patients was done, it shows that $51.43 \%(n=18)$ in Group- $A$ and $42.86 \%(n=15)$ in Group-B were between $5-15$ years of age whereas $48.57 \%(n=17)$ in Group-A and $57.14 \%(n=20)$ in Group-B were between 16-30 years of age, mean+sd was calculated as $14.83 \pm 5.84$ years in Group $-A$ and $15.63 \pm 5.59$ years in Group-B (Table 1).

Table 1: Age distribution $(n=70)$

\begin{tabular}{|c|c|c|c|c|}
\hline \multirow{2}{*}{$\begin{array}{c}\text { Age } \\
\text { (in years) }\end{array}$} & \multicolumn{2}{|c|}{ Group-A ( $\mathrm{n=35}$} & \multicolumn{2}{c|}{ Group-B (n=35) } \\
\cline { 2 - 5 } & No. of patients & $\%$ & No. of patients & $\%$ \\
\hline $05-15$ & 18 & 51.43 & 15 & 42.86 \\
\hline $16-30$ & 17 & 48.57 & 20 & 57.14 \\
\hline Total & 35 & 100 & 35 & 100 \\
\hline Mean+SD & \multicolumn{2}{|c|}{$14.83 \pm 5.84$} & \multicolumn{2}{|c|}{$15.63 \pm 5.59$} \\
\hline
\end{tabular}

Gender distribution of the patients shows that $62.86 \%(\mathrm{n}=22)$ in Group-A and $57.14 \%(n=20)$ in Group-B were male whereas $37.14 \%(n=13)$ in Group-A and $42.86 \%(n=15)$ in Group-B were females (Table 2).

Table 2: Gender distribution $(n=70)$

\begin{tabular}{|c|c|c|c|c|}
\hline \multirow{2}{*}{ Gender } & \multicolumn{2}{|c|}{ Group-A (n=35) } & \multicolumn{2}{c|}{ Group-B (n=35) } \\
\cline { 2 - 5 } & No. of patients & $\%$ & No. of patients & $\%$ \\
\hline Male & 22 & 62.86 & 20 & 57.14 \\
\hline Female & 13 & 37.14 & 15 & 42.86 \\
\hline Total & 35 & 100 & 35 & 100 \\
\hline
\end{tabular}

Comparison between conventional cold steel tonsillectomy versus bipolar diathermy tonsillectomy shows $24.57 \pm 1.42 \mathrm{ml}$ blood loss in Group-A and $11.17 \pm 1.67 \mathrm{ml}$ in Group-B, $\bar{p}$ value was 0.001 . Mean operative time (minutes) was recorded as $24.94 \pm 2.26$ minutes in Group-A and 13.09+1.66minutes in Group-B, p value was 0.0001 (Table 3 ). 
Table 3: Comparison of mean primary blood loss and mean time taken to complete the procedure between conventional cold steel tonsillectomy versus bipolar diathermy tonsillectomy $(n=70)$

\begin{tabular}{|c|c|c|c|c|c|}
\hline \multirow{2}{*}{ Variables } & \multicolumn{2}{|c|}{$\begin{array}{c}\text { Group-A } \\
(\mathbf{n = 3 5})\end{array}$} & \multicolumn{2}{c|}{$\begin{array}{c}\text { Group-B } \\
(\mathbf{n = 3 5})\end{array}$} & \multirow{2}{*}{ P value } \\
\cline { 2 - 5 } & Mean & SD & Mean & SD & \\
\hline Blood loss (ml) & 24.57 & 1.42 & 11.17 & 1.67 & 0.001 \\
\hline Operative time (mins) & 24.94 & 2.26 & 13.09 & 1.66 & 0.0001 \\
\hline
\end{tabular}

\section{DISCUSSION}

Tonsillectomy forms the main bulk of surgery in otolaryngology practice. Cold dissection and bipolar diathermy are the two mostly used techniques. After the advent of non-explosive mixtures, the use of Bipolar diathermy became common with General inhalation anesthesia. This study was planned to compare the techniques of cold steel dissection tonsillectomy and Bipolar electrocautery in our population, so this study may help us to generate evidence for local population and in future the best technique will be preferred with confidence to achieve good perioperative bleeding control and short procedure time. In this study, out of 70 cases (35 in each group), $51.43 \%(n=18)$ in Group-A and $42.86 \%(n=15)$ in Group-B were between $5-15$ years of age whereas $48.57 \%(n=17)$ in Group-A and $57.14 \%(n=20)$ in Group-B were between $16-30$ years of age, mean+sd was calculated as $14.83+5.84$ years in Group-A and $15.63+5.59$ years in Group-B, $62.86 \%(n=22)$ in Group-A and $57.14 \%(n=20)$ in Group-B were male whereas $37.14 \%(n=13)$ in Group-A and $42.86 \%(n=15)$ in Group-B were females, comparison between conventional cold steel tonsillectomy versus bipolar diathermy tonsillectomy shows $24.57 \pm 1.42 \mathrm{ml}$ blood loss in Group-A and $11.17 \pm 1.67 \mathrm{ml}$ blood loss in Group-B, $p$ value was 0.001 . Mean operative time (minutes) was recorded as $24.94 \pm 2.26$ minutes in Group-A and 13.09+1.66 minutes in Group-B, $p$ value was 0.0001 . We compared our results with a previous study, where the average blood loss per operation was $24.6 \pm 6.12 \mathrm{ml}$ in the cold dissection group, whereas it was $10.3 \pm 2.85 \mathrm{ml}$ in the group of bipolar electrocautery with a $P$ value of 0.001 . The average operating time of the cold dissection method was $23.50 \pm 7.10$ minutes compared to bipolar diathermy was $13.50 \pm 3.0$ minutes which is clearly showing that the Bipolar diathermy tonsillectomy is better in term of perioperative blood loss and short procedure time during tonsillectomy than cold dissection method. Shah $\mathrm{SA}^{9}$ and others analyzed Bipolar diathermy tonsillectomy for its safety and postoperative morbidity and showed that time taken by the procedure ranged from 10 to 20 minutes. Intraoperative blood loss ranged between 2 to $5 \mathrm{ml}$. Postoperative pain averaged around $3-5$ on a $1-10$-point scale in $75 \%$ of patients. $80 \%$ of patients were back to normal diet by day 3 after operation. Nine $(3.6 \%)$ patients had a secondary hemorrhage that was managed conservatively and did not need surgical intervention. They concluded that Bipolar diathermy tonsillectomy is an effective and safe technique, especially in children. Adequate experience with the technique is mandatory to achieve the desired goals. Another study ${ }^{10}$ compared the cold and hot dissection methods of tonsillectomy and revealed that out of thirty eight of 43 patients aged between 10 years and 31 years with 21 (55.3\%) males and 17 (44.7\%) females, M:F ratio of 1.2:1. Removal of tonsils by cold dissection took an average of $11.14(\mathrm{SD}=9.89)$ minutes and by diathermy, $9.10(\mathrm{SD}=7.86)$ minutes $(p=0.001)$. Thirty-two $(84.2 \%)$ patients stated that the diathermy site was more painful than the cold dissection side. No postoperative hemorrhage. More eschar was noticed on the diathermy sides with less than $25 \%$ healing compared with the cold blunt dissection sides on the 7th postoperative day. They concluded that from their experience, diathermy tonsillectomy has the advantage of shorter operative time. Another study ${ }^{11}$ evaluated the use of Bipolar diathermy for tonsillectomy and revealed that the average blood loss was less than $4 \mathrm{ml}$ in 100 patients. Most were able to drink and eat by 4 and 10 hours respectively. No primary hemorrhage was recorded; three patients had a secondary hemorrhage. The technique allows accurate coagulation of blood vessel and is an easy procedure to learn. The results of our study in accordance with the above studies show that "Bipolar diathermy tonsillectomy is better method of tonsillectomy with short operative time, minimum primary blood loss when compared with cold steel dissection tonsillectomy".

\section{CONCLUSION}

We concluded that mean Primary Blood loss and mean time taken to complete the procedure were significantly lower in bipolar diathermy tonsillectomy when compared to conventional cold steel tonsillectomy.

\section{LIMITATIONS}

As this study was on small number of patients in one institution so further large-scale studies are required to ascertain accurate results.

\section{SUGGESTIONS / RECOMMENDATIONS}

As we concluded in this study Bipolar Diathermy Tonsillectomy technique is safer and more advantageous so we recommend this technique as a safe method for Tonsillectomy.

\section{CONFLICT OF INTEREST / DISCLOSURE}

There was no conflict of interest of Authors in this study as it was approved from ethical review committee.

\section{ACKNOWLEDGEMENTS}

I acknowledge my worthy Professor and Head of Department Prof. Muhammad Saeed for his valuable guidance during this study.

I also acknowledge Mr. Arsalan for proof reading and composing of this article. 


\section{REFERENCES}

1. Verma R, Verma RR, Verma RR. Tonsillectomy-Comparative Study of Various Techniques and Changing Trend. Indian J Otolaryngol Head Neck Surg. 2017; 69(4):549-58.

2. Anderson J, Paterek E. Tonsillitis [Updated 2019 Jun 28].

3. Sayin I, Cingi C. Recent medical devices for tonsillectomy. Hippokratia. 2012;16(1):11-16.

4. Omrani M, Barati B, Omidifar N, Okhovvat AR, Hashemi SAG. Coblation versus traditional tonsillectomy: a double blind randomized controlled trial. J Res Med Sci. 2012;17(1):45-50.

5. Baek MK, Kim YS, Choi SFI, Woo JH, Lee JH, Kim DY. A pilot randomized comparative study of two diathermy power settings for monopolar microdisecsection and bipolar hemostasis during tonsillectomy. Korean J Otorhinolaryngol Haed Nek Surg. 2016;59(12):836-42.

6. Hong SM, Cho JO, Chae SW, Lee HM, Woo JS. Coblation vs. electrocautery tonsillectomy: a prospective randomized study comparing clinical outcomes in adolescents and adults. Clin Exp Otorhinolaryngol. 2013;6(2):90-3.

7. Zoinon $\mathrm{H}$, Solim R, Daud MKM. Coblation tonsillectomy versus dissection tonsillectomy: a comparison of intraoperative time, intraoperative blood loss and post-operative pain. Med J Malayshia 2014;69:74-8.

8. Ahmad R, Salam F, Khan A, Bahsir F, Atif R. Tonsillectomy in pediatric population; comparison of bipolar electrocautry and cold dissection method. Prof Med J. 2016;23(3):499-503.

9. Shah $S A$, Ghani R. Evaluation of safety of bipolar diathermy tonsillectomy. J Ayub Med Coll Abbottabad. 2007;19(4):94-7.

10. Adoga AA. Cold versus hot dissection tonsillectomies: The Nigerian experience. East Cent Afr J surg. 2011;16(3):64-8.

11. Pang YT, EL-HAKIM H, Rothera MP. Bipolar diathermy tonsillectomy. Clinical Oncology 1994;19(4):355-7.

$\begin{array}{ll}\text { AUTHORSHIP CONTRIBUTION } \\ \text { Adeel Niaz } & \text { Data Collection, Manuscript writing } \\ \text { Muhammad Saeed } & \text { Data Collection } \\ \text { Hafiz Sajjad Hyder } & \text { Statistical Analysis }\end{array}$

